\title{
Investigation of a Pico Turgo Turbine for High-Rise Buildings Using Computational Fluid Dynamics
}

\author{
Wichai Pettongkam ${ }^{1}$, Wirachai Roynarin ${ }^{1} \&$ Decha Intholo ${ }^{1}$ \\ ${ }^{1}$ Engineering Faculty, Rajamangala University of Technology Thanyaburi (RMUTT), Phathumthani, Thailand \\ Correspondence: Wichai Pettongkam, Engineering Faculty, Rajamangala University of Technology Thanyaburi \\ (RMUTT), Phathumthani 12110, Thailand. E-mail: wichai_p@mail.rmutt.ac.th
}

Received: November 29, 2017

doi:10.5539/jsd.v11n1p112

\author{
Accepted: January 4, $2018 \quad$ Online Published: January 30, 2018 \\ URL: https://doi.org/10.5539/jsd.v11n1p112
}

\begin{abstract}
Thailand is a rapidly developing country, and many high-rise buildings are being constructed to satisfy the demands of the increasing populace. The country is located in tropical South East Asia, which means it experiences abundant rainfall during the rainy season. The design of a hydropower system from a waterfall is re-invented in this study using rainwater flowing from the rooftop of a high-rise building to drive a Pico Turgo Turbine. In the building under study, the rooftop is restructured to receive and store $57.6 \mathrm{~m}^{3}$ of rainwater, which is allowed to flow down through a designed pipe of $21 \mathrm{~m}$ head to a Pico Turgo Turbine of $1 \mathrm{~kW}$ capacity. The turbine is fitted with four 10-mm-diameter nozzles that have a $17^{\circ}$ angle of attack between the water jets and the buckets, a $430-\mathrm{mm}$ runner diameter, and 21 buckets with a total capacity of $0.007 \mathrm{~m}^{3}$. The power generated by the device is analysed and compared with a Computational Fluid Dynamics (CFD) simulation under certain boundary conditions. The simulations use the k- $\varepsilon$ turbulent flow model. The bucket is designed according to hydrodynamic theory and parameterised using Bezier polynomials. The theoretical calculation yields $1,310 \mathrm{~W}$ of electricity, the CFD simulation suggests $1,037 \mathrm{~W}$, and the experimental result gives $950 \mathrm{~W}$. The results are analysed according to the efficiency of output, with the CFD simulation representing $79.21 \%$ efficiency whereas the experimental result suggests $72.51 \%$ efficiency. The efficiency of the model is also investigated with respect to flow design and recommendations for future optimisation are presented.
\end{abstract}

Keywords: Pico Turgo Turbine, Computational Fluid Dynamics (CFD), k- $\varepsilon$ turbulent flow model

\section{Introduction}

\subsection{Introduce the Problem}

The real estate business in Thailand, especially regarding residential buildings in the Bangkok Metropolitan area, has significantly transformed building projects across the country since 2000. Developers have shifted housing design projects from 2-3 bedroom bungalows to tall apartment housing designs. In 2015, over 52,000 housing units were completed in the Bangkok area alone, and most of the erected structures were condominiums. A large number of projects were scheduled for completion in 2016 and 2017 (Thai Meteorological Department).

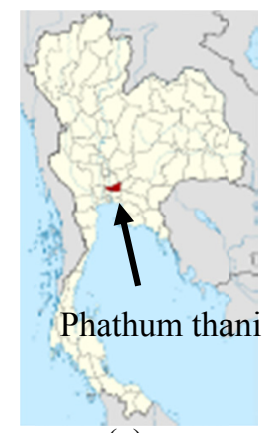

(a)

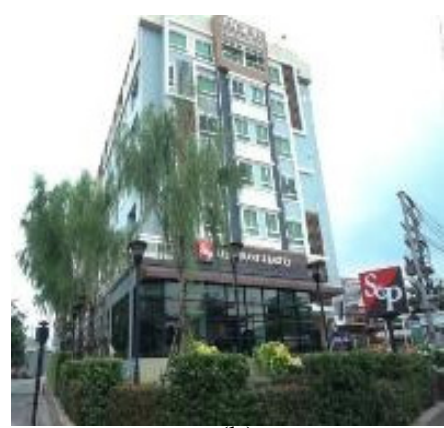

(b)

Figure 1 (a) Phathumthani, Thailand; (b) High-rise Pier 93 building, located in Phathumthani 
This research study was conducted using a focuses on the High-Rise Pier 93 Building, located at in the Klong 4 district of Thanyaburi, Phathumthani which show in (see Figure 1). This location is at the east side of Bangkok, and it is classified as one of the central districts. The region experiences a rainy season that can span from July to October of each year (Abhijit Date., 2012.), and with occasional rainfalls from November to December in some cities. Table 1 shows the distribution of rainfall amount expectations in across the year.

Table 1 . Thailand rainfall by district (mm) (Abhijit Date., 2012)

\begin{tabular}{cccccccc}
\hline Region & July & Aug. & Sept. & Oct. & Nov. & Dec. & Total (1Y) \\
\hline North & $130-210$ & $190-280$ & $210-280$ & $100-140$ & $20-40$ & $<10$ & 1226.3 \\
Northeast & $210-320$ & $200-300$ & $240-330$ & $100-140$ & $15-30$ & $<10$ & 1395.6 \\
Central & $110-190$ & $130-210$ & $260-340$ & $160-200$ & $30-50$ & $<10$ & 1229.7 \\
East & $260-360$ & $190-310$ & $290-400$ & $200-250$ & $40-60$ & $<10$ & 1903.4 \\
Southern & $90-160$ & $100-170$ & $110-170$ & $230-280$ & $330-380$ & $210-260$ & 2724.2 \\
\hline
\end{tabular}

\subsection{Turbine Selection}

Turbines are differentiated according to their operational principles (Deepak Bisen,. 2014.), and can be classified as follows: (1) Reaction turbines, in which the rotor of the turbine is fully immersed in water and enclosed in pressure casing. The imposed pressure exacts a lifting force on the rotor causing the rotation of the runner. (2) Gravity turbines, which are driven by the weight of water entering the top of the turbine and falling to the bottom. (3) Impulse turbines, which are driven by high-speed water jets. These are widely used for micro- and pico-hydropower installations, because they have several advantages such as their simple design and greater tolerance of sand and other particles within the water (Hermod Brekke, 2011). Impulse turbines can be further classified into three main types: the Pelton, Turgo, and Crossflow turbines. Crossflow turbines have low running speeds, but require substantial speeds to drive the generator. The efficiency of crossflow turbines has been measured at around $80 \%$ under laboratory conditions, whereas the efficiency of the Turgo turbine has been reported to be close to $90 \%$ (S.J. Williamson., 2011.).

The Turgo turbine is similar to the Pelton, but the jet strikes the plane of the runner at an angle (typically $15-25^{\circ}$ ) so that the water enters the runner on one side and exits on the other. Therefore, the flow rate is not limited by the discharged fluid interfering with the incoming jet (as is the case with Pelton turbines). As a consequence, Turgo turbines can have smaller diameter runners and rotate faster than Pelton turbines for an equivalent flow rate (A.H. Elbatran, 2015).

The Turgo turbine is selected for the design installation because it is able to function normally under variable seasonal flows and is efficient for a range of heads (Bryan Patrick Ho-Yan., 2012). The machine is ideal for remote home-sites. In this study, the direct-drive generator is used because it is suitable for heads of 6-21 m.

The pressurised water emerging from the end of the nozzle creates a force that impacts the cup of the Turgo turbine and drives the runner, which is connected to a runner shaft, to produce electrical power. The quantity of electricity is dependent on the head and flow rate: a steady flow from a given head will produce consistent electricity. The pressure or head is generated by the difference in elevation between the water storage and the turbine. The general classification of hydropower turbines can be stated in terms of capacity of each machine and the different ratings of hydro turbine classes (Kyle Gaiser., 2016.).

This research study considered a Low Head Pico Hydro Turbine. The turbine type depends mainly on the characteristic head and flow situation available at the site. The hydrostatic pressure (Pg) created from the head is given by

$$
P_{g}=\rho g H
$$

where $\rho$ is the water density, $g$ is acceleration due to gravity, and $H$ is the head of water. The continuity equation can be derived from Bernoulli's equation, assuming that the flow is steady and laminar and the fluid is incompressible. Assuming negligible viscosity, the Bernoulli equation is given by

$$
P+\frac{1}{2} \rho v^{2}+\rho g z=\text { const }
$$




\section{Materials and Methods}

The processes in this study are shown in Figure 2. And considers design conditions for the water head and water flow rate. The design proceeds according to theoretical calculations to determine the size of the turbine runner, the bucket space, and the amount of energy generated from the potential energy and water flow rate. The next step is to create a 3D study model for the simulation process using computational fluid dynamics (CFD). A prototype was built for testing, and the output was compared with the results from the theory and CFD.

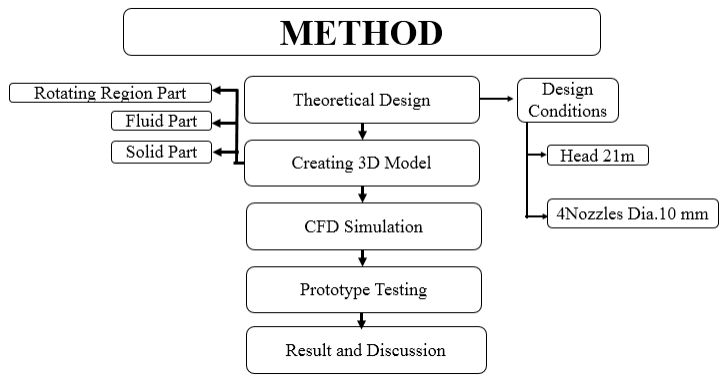

Figure 2. Process flowchart

A reservoir was designed for the rooftop to collect and store rainwater which would be passed to the turbine machine. The Pier 93 building is shown in Figure 3 (a). The rooftop was initially designed as shown in Figure 3(b). The rooftop was reconstructed and enlarged to collect up to $57.6 \mathrm{~m} 3$ of rainwater, as shown in Figure 3 (c). The storage area can collect $354.15 \mathrm{~m} 3 /$ year of rainwater.

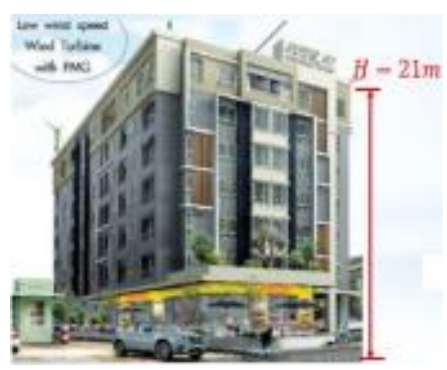

(a)

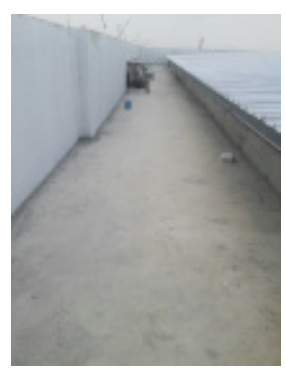

(b)

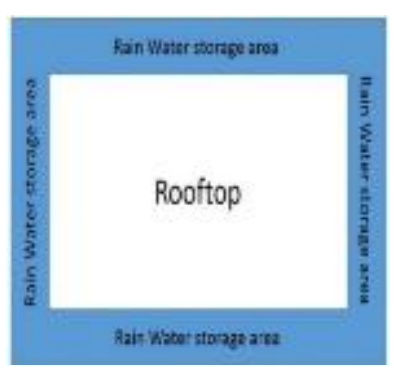

(c)

The quantitative theoretical analysis is as follows.

The Pico Turgo turbine has four nozzles of $10 \mathrm{~mm}$ diameter. The rate of water is $0.0062 \mathrm{~m}^{3} / \mathrm{s}$ or $22.3 \mathrm{~m}^{3} / \mathrm{h}$. The building is $21 \mathrm{~m}$ high. The annual volume of water collected on the roof is $354.15 \mathrm{~m}^{3}$.

\subsection{Runner Design \& Parameterisation}

The hydraulic head $H$ can be calculated at any location using the elevationz, pressurep, and velocity $v$ :

$$
H=z+\frac{p}{\rho g}+\frac{v^{2}}{2 g}
$$

where $\rho$ is the density of the fluid and $g$ is gravity. The mean velocity of the free jet from the nozzle is determined from the net head as:

$$
c=\varphi \sqrt{2 g H} \approx 0.97 \sqrt{2 g H}
$$

where $\varphi$ is the efficiency of the nozzle (generally $0.97-0.98$ ). The flow rate $Q$ for a jet diameter of $d$ can be calculated using:

$$
Q=\frac{\pi}{4} d^{2} c
$$

At optimum efficiency, the circumferential speed of the runner is connected with the jet velocity as:

$$
u_{1} \approx(0.46-0.47) c
$$


Hence, the diameter of the runner is

$$
D_{s}=\frac{60 u_{1}}{\pi n}
$$

where $n$ is the runner speed in rpm. The bucket is drawn with the aid of a Bezier curve. At a given radial distance $r$, the peripheral velocity of the runner is $u_{1}$. At optimum efficiency, the flow exits with zero circumferential velocity (Cobb, B. R., 2011). The performance variables are the turbine power $P$, overall turbine system efficiency $\eta$, and gross head $H_{g}$.

$$
P=T \omega=\eta \rho g Q H_{g}
$$

where $P, T$, and $\omega$ denote the power, torque, and angular velocity of the Turgo water turbine, $\rho$ is the density of the rainwater, and $g$ is the gravitational constant.

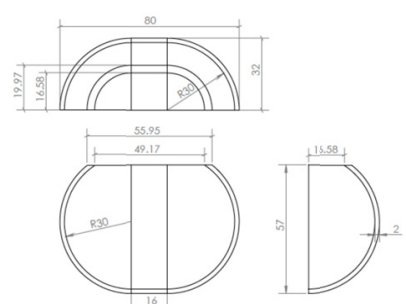

(a)

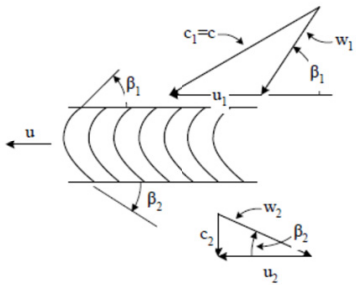

(b)

Figure 4. (a) Bucket of Turgo turbine; (b) Velocity triangles

Figure 4(a) shows the bucket used in the Turgo turbine and Figure 4(b) shows velocity triangles of the water jet impacting the bucket of the turbine (John S. Anagnostopoulos., 2007). The power is the product of the rotational speed at maximum power and the torque. In this research, the angle at which the water strikes the blade is $17^{\circ}$.

\subsection{Computational Fluid Dynamics (CFD)}

The CFD involves numerical modelling and analysis of the flow in a Turgo runner, along with a preliminary design. To achieve this, the inner surface of a blade was initially designed according to hydrodynamic theory and Bezier polynomials (Wilson, P. N., 1967.) were used to improve the hydraulic efficiency of the initial design, clarify the main dimensions of the examined runner, and identify the nominal operation conditions.

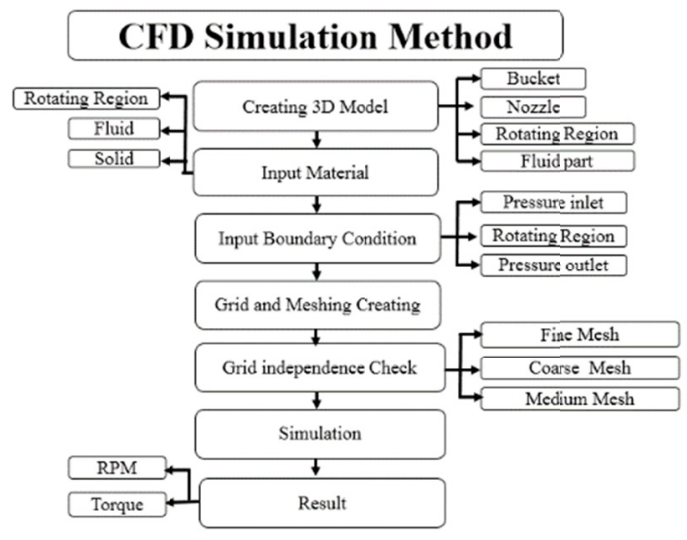

Figure 5. Shows the CFD simulation method

Figure 5 shows the CFD simulation method, starting with the creation of a 3D study model. This study model consists of the bucket, nozzle, rotating region, and fluid part. The materials considered in the CFD processes are the fluid, solid, and rotating regions. The specific boundary conditions determine the input part of the nozzle to indicate the pressure inlets, which apply different pressures under testing, whereas the pressure outlets show the 
barometric pressure. In this input boundary process, the water stream from the nozzle is injected into the rotating region. A grid and mesh were created for the different parts of the study model. The mesh was determined by a grid-independent check using coarse, medium, and fine meshes to acquire the torque and rotation speed (rpm). CFD uses numerical methods to solve the governing equations describing the behaviour of fluids (Crewdson, E., 1922).

The governing equations of conservation: the continuity equation, the momentum equation, and the energy equation. The governing equations, including the Navier-Stokes equation, are presented in their most general form below.

Continuity equation:

$$
\frac{\partial \rho}{\partial t}+\nabla \cdot(\rho \vec{u})=0
$$

Momentum equation:

Expressed as the Navier-Stokes equation:

$$
\frac{\partial}{\partial t}(\rho \vec{u})+\rho(\vec{u} \cdot \nabla \vec{u})=-\nabla p+\nabla \cdot \tau+S_{m}
$$

where the stress tensor $\tau$ is related to the strain rate by

$$
\tau=\mu\left(\nabla \vec{u}+(\nabla \vec{u})^{T}-\frac{2}{3} \delta \nabla \vec{u}\right)
$$

Energy equation:

$$
\frac{\partial}{\partial t}\left(\rho h_{t}\right)-\frac{\partial \rho}{\partial t}+\nabla \cdot\left(\rho \vec{u} h_{t}\right)=\nabla \cdot(\vec{u} \cdot \tau)+\vec{u} \cdot S_{m}+S_{e}
$$

where the total enthalpy $h_{t}$ is related to the static enthalpy $h_{s}$ by:

$$
h_{t}=h_{s}+\frac{1}{2} \vec{u}
$$

Table 4. Turgo turbine boundary specifications

\begin{tabular}{ccc}
\hline Parameter name & Units & Parameter Value \\
\hline Inlet Total Pressure & Bar & $1-4$ \\
Inlet Total Temperature & $\mathrm{K}$ & 320 \\
Angular Velocity & $\mathrm{rad} / \mathrm{s}$ & Free spin \\
Cup Number & & 24 \\
Nozzle Number & & 4 \\
Viscosity & $\mathrm{Pa}-\mathrm{s}$ & 0.001003 \\
Specific heat & $\mathrm{J} / \mathrm{kg} \cdot \mathrm{K}$ & 4182 \\
Working fluid & & Water \\
Density & $\mathrm{kg} / \mathrm{m}^{3}$ & 998.2 \\
Emissivity & & 1 \\
\hline
\end{tabular}

The development of CFD methods to analyze complex phenomena such as multiphase, free-surface, highly turbulent flows for a large number of design variations in a reasonable timescale (Anagnostopoulos, J. H .,2011). Recent developments in CFD codes mean that simulations of this nature show good agreement with experimental data (Audrius Židonis., 2011), giving confidence in the reliability of the numerical results produced when simulating complex phenomena. The numerical results were validated by an experimental test (Audrius Židonis., 2012). The flow features of the Turgo turbine were also investigated. The components of the Turgo turbine were separated from the assembly model, namely the nozzle passage and runner passage. The boundary conditions of the Turgo turbine are presented in Table 4. 


\section{BOUNDARY FOR CFD SIMULATIONS}

Figure 6 shows the three major sections analysed in this study: the nozzle, bucket, and rotating region. The efficiency of the Turgo turbine can be affected by the bucket shape. However, an accurate technique for modelling the flow in a rotating Turgo runner is required for further improvements and design validations.

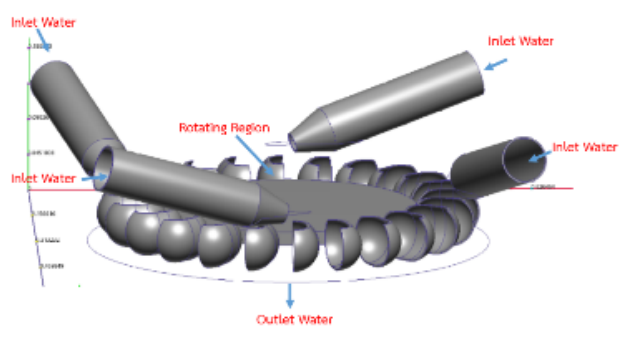

Figure 6. Turgo turbine computational domain and boundary conditions

Transient simulations were conducted involving the interaction of a rotating bucket or runner. The torque in Turgo turbines is periodic, as each bucket is subjected to the same loading by the jet when operated in steady conditions (H. K. Versteeg., 2007). Many researchers used the minimum number of buckets required to simulate the torque on a single bucket, and then constructed the torque on the complete runner using this periodicity. The most widely used turbulence models is $\mathrm{k}-\varepsilon$ models include additional separate equations for the turbulent kinetic energy (k) and turbulent dissipation rate $(\varepsilon)$.

\subsection{Grid Independence Check}

CFD uses an Eulerian fluid flow field specification (Audrius Židonis., 2015). The domain is discretised using cell-vertex numerics (finite volume elements). These may be unstructured tetrahedral elements, which are used to capture the complex geometry of rotating domains and to allow automatic meshing for any future geometry modifications.

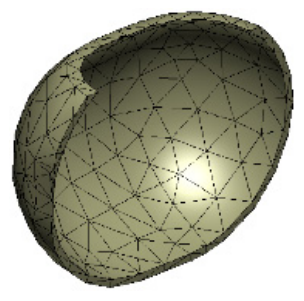

(a)

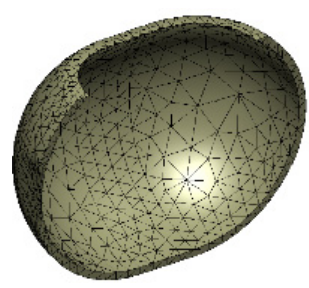

(b)

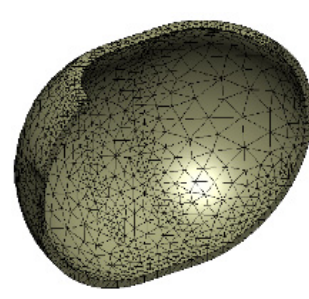

(c)

Figure 7. Bucket grid dependency of Turgo turbine (a)Coarse mesh (b) Medium mesh (c) Fine mesh

For the three mesh intensities, denoted as the "Coarse mesh", "Medium mesh", and "Fine mesh", each component of the Turgo turbine (i.e. nozzle, runner, rotating region) was constructed and adjusted. Figure 7 shows the grid refinement of a bucket, and Figure 8 shows the assembly model grid density of nozzles, buckets, and the rotating region of a Turgo turbine generated by a commercial CFD program.

Periodic boundary conditions are applied to simulate the flow through a bucket. At the interface between the exit of the runner and the outlet of the nozzle domain, the convergence of the nozzle assembly and rotating region is depicted in Figure 9 and Table 5. The mixing plane is widely used because of its efficiency in simulating blade-row interactions in the steady state. Grids for the construction of the Turgo turbine component were generated, and appear to converge at around 3,500,000 cells, with the angular speed converging to $190 \mathrm{rpm}$. 


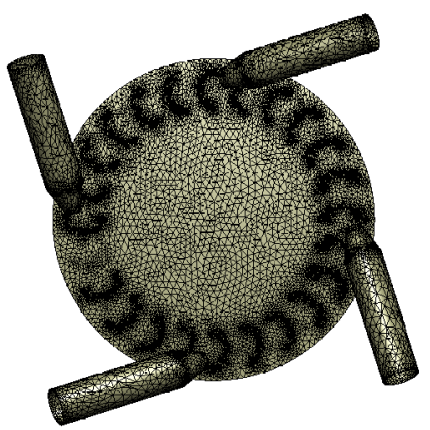

Figure 8. Grid density of Turgo turbine nozzle, cup, and rotating region

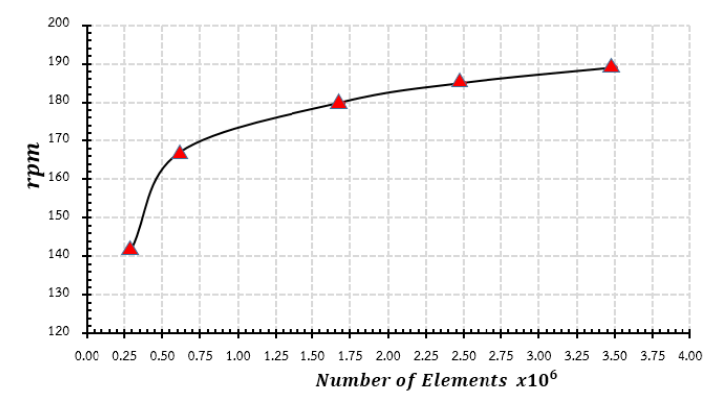

Figure 9. Grid dependency of pico Turgo turbine

Table 5. Grid convergence

\begin{tabular}{cc}
\hline Grid number $\times 10^{6}$. & $\mathrm{rpm}$ \\
\hline 0.25 & 141 \\
0.50 & 162 \\
0.75 & 170 \\
1.00 & 172 \\
1.50 & 178 \\
2.50 & 185 \\
3.50 & 189 \\
\hline
\end{tabular}

After calculating and simulating the flow of water turbulence using CFD, the testing apparatus shown in Figure 10 was assembled to measure the production of electrical power.

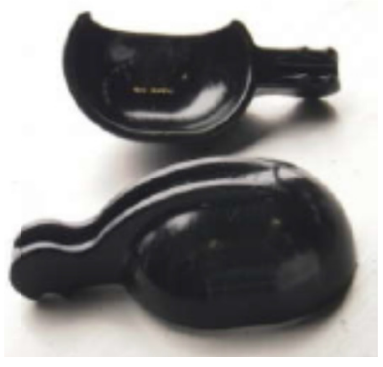

(a)

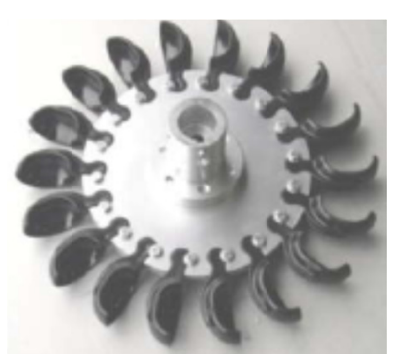

(b)

Figure. 10 Pico Turgo turbine(a) Prototype buckets (b) Prototype buckets with runner

Figure 11 shows the complete pico Turgo turbine testing apparatus. The testing buckles in Figure 11(a) are connected to the runner shaft. The energy and efficiency of the test apparatus were measured by installing a 
torque sensor at point $\mathrm{A}$ and a rotation sensor at point $\mathrm{B}$. The torque sensor was used to measure the torque obtained by the water jets from the nozzles impacting on the buckets. The rotation of the turbine shaft at point $\mathrm{B}$ determines whether the turbine shaft is being turned by this torque. The torque from the rotation is transmitted to the permanent magnet generator (PMG) shown in Figure 11(b). The water in the testing apparatus was circulated using a water motor and pump to create water pressure in the four 10-mm nozzles (see Figure 11(c)). Figure 11(d) shows water from the nozzles impacting the buckets. The power from the test water turbine was $\mathrm{P}_{\text {out }}=\mathrm{T} \omega$, where $\mathrm{T}, \omega$ are acquired from the water turbine.

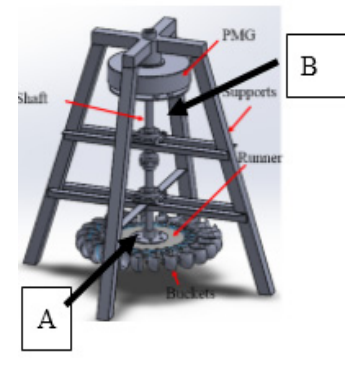

(a)

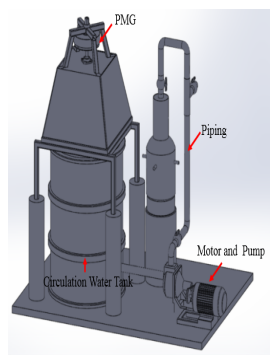

(b)

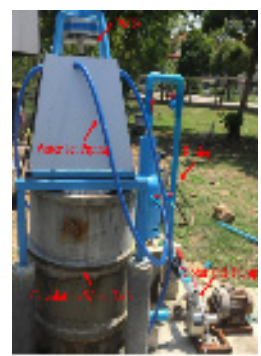

(c)

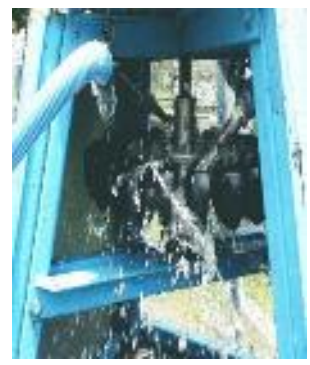

(d)

Figure 11. Pico Turgo turbine testing: (a) 3D testing buckets connected to PMG;

(b) Pressure water circulation system; (c) water circulation system connected to the nozzles

(d) Water from nozzles impacting the buckets

\section{Results}

Table 6 shows experimental data obtained with a 10-mm nozzle diameter, where the power of the water turbine is dependent on the flow rate and water head. The experimental data obtained three times testing for data validating. The results show that, at the lowest height of $5 \mathrm{~m}$, the flow rate of $11.21 \mathrm{~m}^{3} / \mathrm{h}$ generates $101.39 \mathrm{~W}$ while the flow rate of $22.95 \mathrm{~m}^{3} / \mathrm{h}$ generates $950.18 \mathrm{~W}$ expectively.

Table 6. Power from experimental tests

\begin{tabular}{ccccccc}
\hline $\begin{array}{c}\text { Nozzle } \\
\text { Dia. } \\
(\mathrm{mm})\end{array}$ & $\begin{array}{c}\text { Head } \\
(\mathrm{m})\end{array}$ & $\begin{array}{c}\text { Flow rate } \\
\left(\mathrm{m}^{3} / \mathrm{h}\right)\end{array}$ & $\begin{array}{c}\text { Test } \\
1\end{array}$ & $\begin{array}{c}\text { Test } \\
(\mathrm{W})\end{array}$ & $\begin{array}{c}\text { Test } \\
(\mathrm{W})\end{array}$ & $\begin{array}{c}\text { Power } \\
(\mathrm{W})\end{array}$ \\
\hline & 5 & 11.21 & 102.82 & 98.75 & 102.70 & $\begin{array}{c}\text { Ave. } \\
(\mathrm{W})\end{array}$ \\
& 7 & 13.21 & 183.52 & 181.64 & 183.48 & 182.86 \\
& 9 & 15.02 & 265.32 & 268.55 & 265.90 & 266.59 \\
10 & 11 & 16.61 & 360.24 & 362.57 & 357.85 & 360.22 \\
& 13 & 18.05 & 461.28 & 464.39 & 357.85 & 462.80 \\
& 15 & 19.39 & 572.64 & 575.12 & 573.07 & 573.61 \\
& 17 & 20.64 & 691.77 & 693.53 & 690.91 & 692.07 \\
& 19 & 21.83 & 816.33 & 818.31 & 818.52 & 817.72 \\
& 21 & 22.95 & 925.32 & 949.82 & 948.38 & 950.18 \\
& & & & & \\
\hline
\end{tabular}

Table 7 shows data obtained with a $10-\mathrm{mm}$ nozzle diameter, where the power of the water turbine is dependent on the flow rate and water head. The results show that, at the lowest height of $5 \mathrm{~m}$, the flow rate of $11.21 \mathrm{~m} 3 / \mathrm{h}$ generates $152.24 \mathrm{~W}$ in theory, $138.54 \mathrm{~W}$ using the CFD method, and $101.39 \mathrm{~W}$ in practical experiments. 
Table 7. Power from theoretical calculations, CFD simulations, and experimental tests

\begin{tabular}{cccccc}
\hline $\begin{array}{c}\text { Nozzle } \\
\text { Dia. } \\
(\mathrm{mm})\end{array}$ & $\begin{array}{c}\text { Head } \\
(\mathrm{m})\end{array}$ & $\begin{array}{c}\text { Flow rate } \\
\left(\mathrm{m}^{3} / \mathrm{h}\right)\end{array}$ & $\begin{array}{c}\text { Power } \\
\text { Theory } \\
(\mathrm{W})\end{array}$ & $\begin{array}{c}\text { Power } \\
\text { CFD } \\
(\mathrm{W})\end{array}$ & $\begin{array}{c}\text { Power } \\
\text { Exp. } \\
(\mathrm{W})\end{array}$ \\
\hline & 5 & 11.21 & 152.24 & 138.54 & 101.39 \\
& 7 & 13.21 & 252.19 & 229.49 & 182.86 \\
& 9 & 15.02 & 367.66 & 334.57 & 266.59 \\
10 & 11 & 16.61 & 496.78 & 452.07 & 360.22 \\
& 13 & 18.05 & 638.25 & 580.81 & 462.80 \\
& 15 & 19.39 & 791.07 & 719.87 & 573.61 \\
& 17 & 20.64 & 954.45 & 868.55 & 692.07 \\
& 19 & 21.83 & 1127.74 & 1026.24 & 817.72 \\
& 21 & 22.95 & 1310.41 & 1192.47 & 950.18 \\
\hline
\end{tabular}

At the highest head of $21 \mathrm{~m}$, the flow rate of $22.95 \mathrm{~m} 3 / \mathrm{h}$ generates $1310.41 \mathrm{~W}$ in theory, $1192.47 \mathrm{~W}$ using the CFD method, and $950.18 \mathrm{~W}$ in actual testing.

The CFD simulation produces two main results, namely the rotation of the runner $(\omega)$ and the torque (T) of the turbine. Hence, the power $(\mathrm{P})$ can be calculated using the formula $\mathrm{P}=\mathrm{T} \omega$. In addition, the CFD simulation results depict the streamlines, water velocity, and water velocity distribution on the bucket. The CFD simulations were validated by the actual test results, which show a $6.7 \%$ difference in power. This verifies that the proposed concept and method are feasible, and that CFD simulations can be used to assist the design.

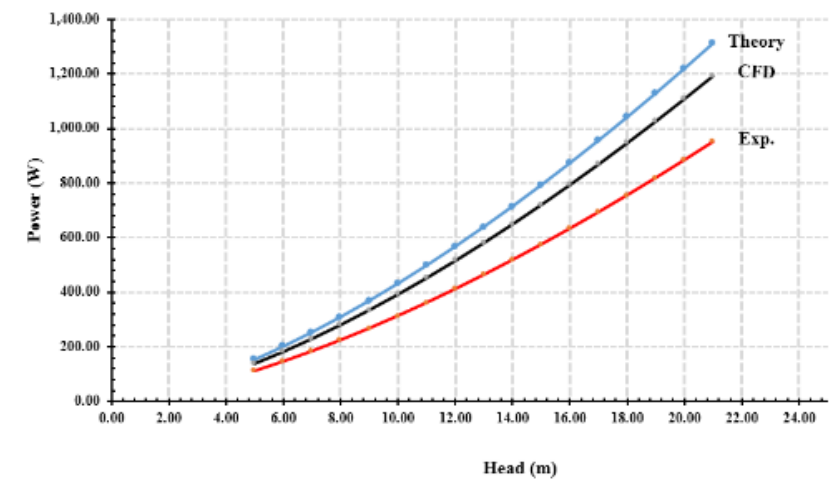

Figure 12. Comparison of power output between theoretical, CFD, and experimental results

Figure 12 compares the power output given by the theoretical calculations, CFD, and experiments. There is a $20.31 \%$ difference between CFD and the test results, whereas the theoretical and CFD method differ by $8.3 \%$.

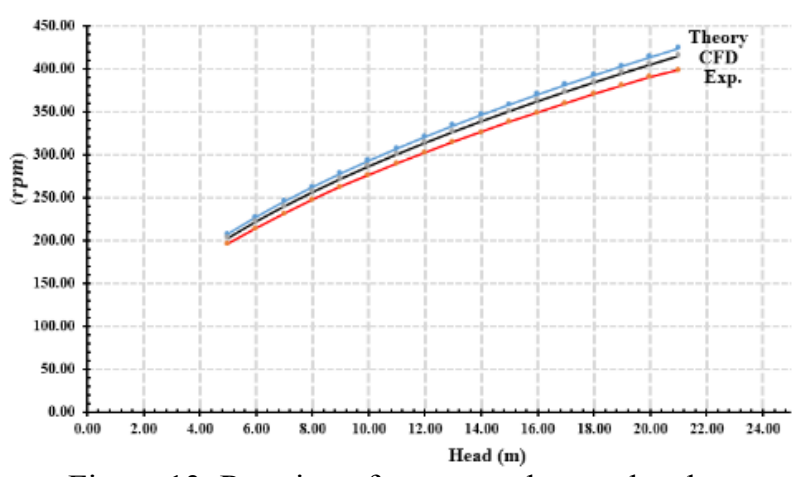

Figure 13. Rotation of runner and water head 
Figure 13 shows the relationship between the rotation of the runner and the water head. The turbine operates at approximately 200-420 rpm. The theoretical, CFD, and test results are $206.86 \mathrm{rpm}, 202.48 \mathrm{rpm}$, and $195.53 \mathrm{rpm}$, respectively.

The power obtained in the experiment and an annual rainwater collection is $350 \mathrm{~m} 3$ indicate that $950.18 \mathrm{~W} \mathrm{x}$ $15.87 \mathrm{~h}=15.08 \mathrm{kWh} /$ year can be generated.

In addition, the Pier 93 building has 79 rooms. The electricity that could be generated if the wastewater from each apartment was channelled to the turbine, assuming that each apartment had a storage facility of around 150 $\mathrm{L}$, is listed in Table 7 for various water head heights.

Table 7. Power from wastewater

\begin{tabular}{ccccc}
\hline $\begin{array}{c}\text { Head } \\
(\mathrm{m})\end{array}$ & Floor & $\begin{array}{c}\text { Volume } \\
\left(\mathrm{m}^{3} / \text { year }\right)\end{array}$ & $\begin{array}{c}\text { Power } \\
(\mathrm{kWh} / \text { day })\end{array}$ & $\begin{array}{c}\text { Power } \\
(\mathrm{kWh} / \text { year })\end{array}$ \\
\hline 6 & 3 & 711.75 & 0.0231 & 8.42 \\
9 & 4 & 711.75 & 0.0424 & 15.47 \\
12 & 5 & 711.75 & 0.0652 & 23.82 \\
15 & 6 & 711.75 & 0.0912 & 33.29 \\
18 & 7 & 711.75 & 0.1198 & 43.76 \\
& & & & \\
& & & Total & 124.76 \\
\hline
\end{tabular}

\subsection{Flow Modelling}

The liquid flow in the rotating runner of an impulse turbine is complex and unsteady.

Figure 14 shows streamlines of water jets discharged from the $10 \mathrm{~mm}$ nozzles.

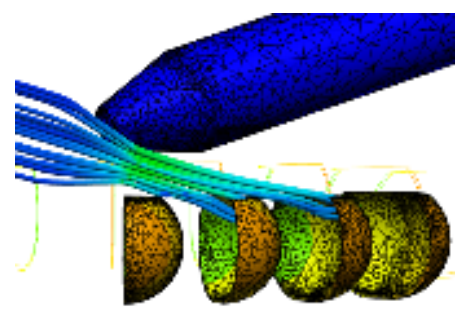

Figure 14. Streamline of water flow in a bucket

The particle flows out of the bucket, as shown in Figures 15 and 16. Particles that pass by the reference blade or impinge on the next blade are not counted.

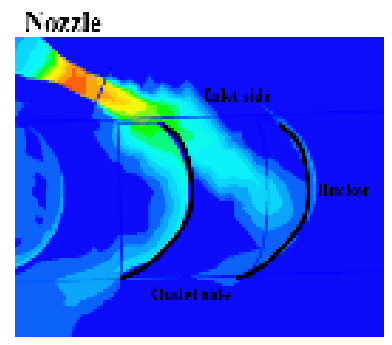

(a)

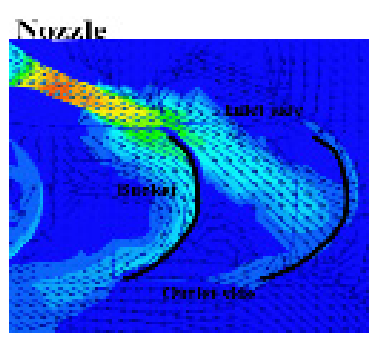

(b)

Figure 15. Velocity contours on Turgo water turbines (a) Flow velocity (b) Vector velocity 


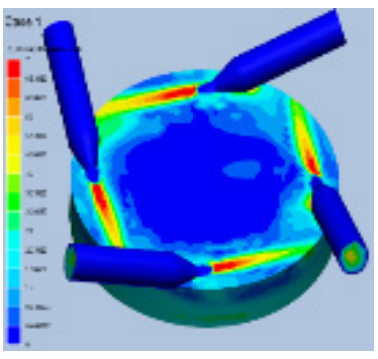

(a)

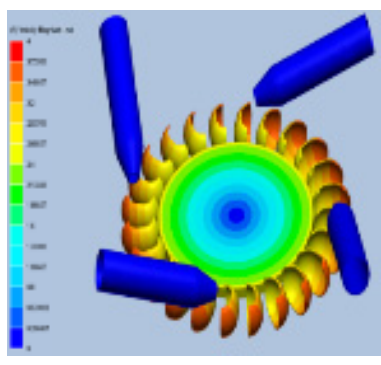

(b)

Figure 16 Velocity distribution on Turgo water turbines

(a) Rotating region (b) Buckets

Figure 17 shows the flow velocity contours of water on the buckets. The highest velocity impacts on the middle bucket, because the nozzles are adjusted for water streamlines to impact on this bucket. The counter-clockwise vector direction of the velocity profile contours is shown in Figure 18.

Figure 18(a) shows the average velocity profile on the bottom, middle, and top buckets. The velocity on the bottom bucket has the highest turbulence; therefore, this velocity is unstable.

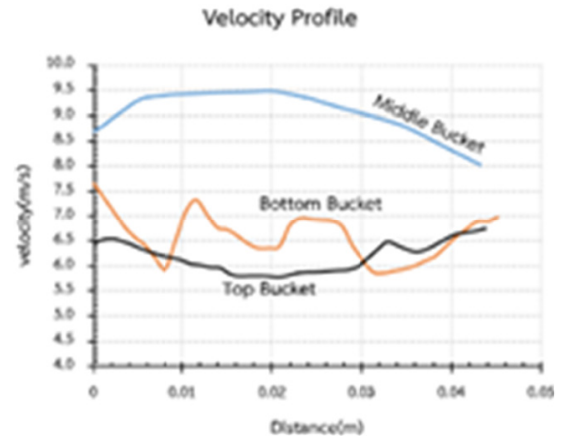

(a)

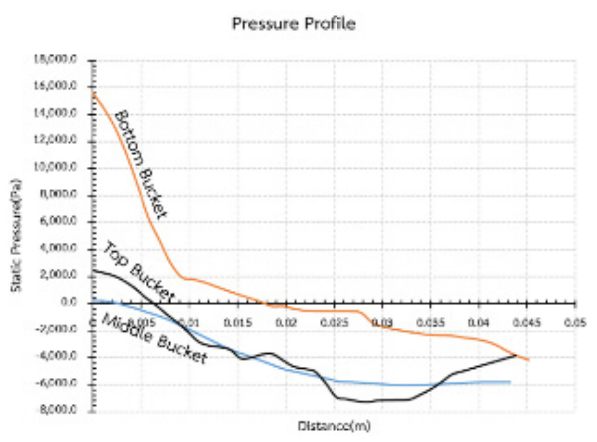

(b)

Figure 17. Pressure and velocity profiles for the top, middle, and bottom buckets

(a) Velocity profile (b) Pressure profile

High pressure acts on the back bucket and decreases through the front of the next bucket, as shown in Figure 18(b). The highest pressure occurs on the bottom bucket, whereas the lowest pressure and highest velocity occur on the middle bucket. Figure 21 shows the flow velocity contours on the top, middle, and bottom buckets.

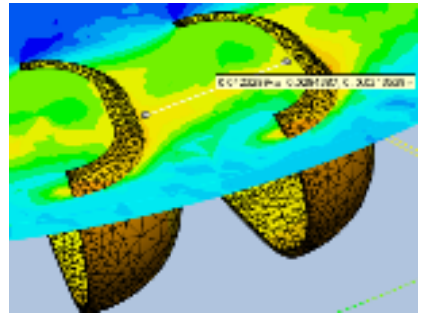

(a)

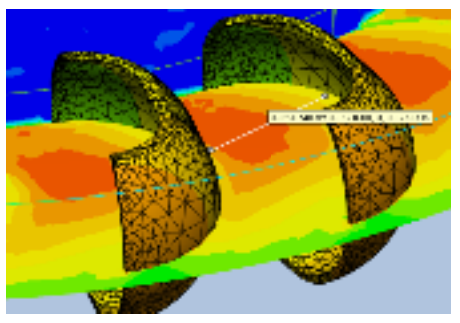

(b)

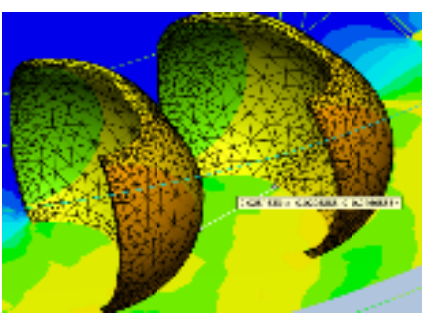

(c)

Figure 18. Flow velocity contours of Turgo water turbine (a) Top bucket (b) Middle bucket(c) Bottom bucket

\section{Discussion}

The effectiveness of the selected hydro-turbine was investigated through theoretical calculations, CFD, and an 
experimental test. The results show that pico Turgo turbines are suitable for hydropower applications in high-rise buildings.

The buckets for pico Turgo turbines were designed by applying hydrodynamic theory. This research project developed a low-head turbine that can convert rainfall or wastewater into electric power in high-rise buildings, thus reducing their grid dependence. We considered annual rainwater input to a rooftop storage facility of 354.15 $\mathrm{m}^{3}$ and a building height of $21 \mathrm{~m}$. At a constant discharge rate of $22.95 \mathrm{~m}^{3} / \mathrm{h}$, the theoretical calculations indicate that a pico Turgo turbine could generate $1,310.41 \mathrm{~W}$ of electricity. The use of CFD to simulate the same flow design gave a result of $1,192.47 \mathrm{~W}$, and an experiment using a prototype design generated $950.18 \mathrm{~W}$. The efficiency of the pico Turgo turbine in the CFD simulation is $79.21 \%$, whereas that in the experiment is $72.51 \%$. The lower value of the test result is due to losses in the design system, such as head loss and friction loss.

The CFD simulation results give two main results: by determining the rotation of the runner $(\omega)$ and the torque (T) of the turbine, we can compute the power of the turbine $(\mathrm{P}=\mathrm{T} \omega)$. In addition, the CFD simulations give streamlines, the water velocity, and the velocity distribution on the buckets.

The CFD simulations were validated by actual testing that shows a $6.7 \%$ difference in power results. This design concept and method is feasible, and the use of CFD simulations is less costly than conventional design processes.

\section{Recommendations}

The ability to use wastewater from each apartment in the building should be further investigated. This water could be collected, stored, and eventually passed down to the sewage through the same pipe as for the pico Turgo turbine. The results of this research show that this will add to the increased running time of the machine, thereby generating more electricity.

To optimise the running speed, numerous tests should be conducted using various angles of attack and numbers of cups. This study has only investigated one particular angle. Although a qualitative result was obtained, there are numerous possibilities for optimising the angle of attack of the nozzle to the runner.

\section{Acknowledgments}

I would like to thank everyone who participated in this study, and particularly the Energy Research and Service Center (ERSC) of the engineering faculty, RMUTT, who supported my work and helped me to obtain quality results. I am also grateful to my supervisor, Wirachai Roynarin, for his patience and support in overcoming numerous obstacles faced in this research.

\section{References}

Anagnostopoulos, J. H. (2011). Development and laboratory testing of improved Action and Matrix hydro turbines designed by advanced analysis and optimization tools. Small Hydro Going Smart Conference.

Anagnostopoulos, J. S., \& Papantonis, D. E. (2007). Flow Modeling and Runner Design Optimization in Turgo Water Turbines. International Journal of Mechanical, Aerospace, Industrial, Mechatronic and Manufacturing Engineering, 1(4).

Bisen, D., Shukla, S. K., \& Sharma, P. K. (2014). Review Paper on Nozzle in Hydro-Turbine. International Journal of Advanced Technology in Engineering and Science, 2(8).

Brekke, H. (2001). Hydraulic Turbines Design, Erection and Operation. Endringsdato.

Bryan Patrick Ho-Yan. (2012). Design of a Low Head Pico Hydro Turbine for Rural Electrification in Cameroon. Master Thesis.

Cobb, B. R., \& Sharp, K. V. (2011). Impulse (Turgo and Pelton) turbine performance characteristics and their impact on pico-hydro installations. Renewable Energy, 36(5), 1379-1391.

Cobb, B. R., \& Sharp, K. V. (2013). Impulse (Turgo and Pelton) turbine performance characteristics and their impact on pico-hydro installations. Renewable Energy, 50, 959-964. https://doi.org/10.1016/j.renene.2012.08.010

Crewdson, E. (1922). Design and Performance of a New Impulse Water-Turbine. Minutes of Proceedings of the Institution of Civil Engineers. https://doi.org/10.1680/imotp.1922.14574

Date, A., Date, A., \& Akbarzadeh, A. (2012). Performance Investigation of a Simple Reaction Water Turbine for Power Generation from Low Head Micro Hydro Resources. Smart Grid and Renewable Energy, pp 239-245. https://doi.org/10.4236/sgre.2012.33033

Elbatran, A. H., Yaakob, O. B., Ahmed, Y. M., \& Shabara, H. M. (2015). Operation, performance and economic 
analysis of low head micro-hydropower turbines for rural and remote areas: A review. Renewable and Sustainable Energy Reviews, 40-50. https://doi.org/10.1016/j.rser.2014.11.045

Gilbert Gilkes \& Gordon Ltd. (2016). Gilkes Turgo Impulse Hydro Turbine.

Kyle Gaiser, Paul Erickson, Pieter Stroeve, Jean-Pierre. (2016). An experimental investigation of design parameters for pico-hydro Turgo turbines using a response surface methodology. Renewable Energy Renewable Energy, 406-418. https://doi.org/10.1016/j.renene.2015.06.049

Thai Meteorological Department, https://www.tmd.go.th

Versteeg, H. K., \& Malalasekera, W. (2007). An Introduction to Computational Fluid Dynamics (2nd ed.). Pearson Education Limited, Second edition published.

Williamson, S. J., Stark, B. H., \& Booker, J. D. (2011). Low Head Pico Hydro Turbine Selection using a Multi-Criteria Analysis. World Renewable Energy Congress 2011. https://doi.org/10.3384/ecp110571377

Wilson, P. N.(1967). A High Speed Impulse Turbine.

Židonis, A. (2015). Optimisation and Efficiency Improvement of Pelton Hydro Turbine Using Computational Fluid Dynamics and Experimental Testing. PhD Thesis.

Židonis, A., \& Aggidis, G. A. (2012). Identifying the Optimum Number of Buckets Using CFD. Lancaster University Renewable Energy Group and Fluid Machinery Group, Engineering Department.

Židonis, A., Benzon, D. S., \& Aggidis, G. A. (2011). Development of hydro impulse turbines and new opportunities. Renewable and Sustainable Energy Reviews, 51, 1624-1635. https://doi.org/10.1016/j.rser.2015.07.007

\section{Copyrights}

Copyright for this article is retained by the author(s), with first publication rights granted to the journal.

This is an open-access article distributed under the terms and conditions of the Creative Commons Attribution license (http://creativecommons.org/licenses/by/4.0/). 